\title{
Resin Impregnation as Basic Tool for the Microanalysis of Microbial Habitats in Soils
}

Thilo N.H. Eickhorst

\author{
University of Bremen, Faculty of Biology/Chemistry, Soil Microbial Ecology, Bremen, Germany
}

The matrix of soils is formed by the arrangement of the solid compartment mainly consisting of minerals and organic matter. The resulting pore space is either filled with soil water or soil air and serves as living space for soil microorganisms. Dynamics of soil physical structure such as swelling and shrinkage or compaction alter the arrangement of pore networks and may affect the living conditions in these microbial habitats. In addition bio-geochemical features influence the microbial populations and their physiological activity within their habitats. These are various redox conditions, supply of nutrients or pollutants.

Both physical and chemical features directly influence the living conditions in microbial habitats in soil related to their spatial arrangement. In order to analyze these influences the microanalysis of the spatial distribution of soil microorganisms is of great importance. Therefore the molecular detection technique of fluorescence in situ hybridization (FISH) has been combined with micropedological methods [1]. This allows the utilization of oligonucleotide probes being specific for certain groups of microorganisms and analyze their arrangement in the undisturbed soil matrix. The combined micropedological methods are based on resin impregnation following the dehydration of the moist soil samples with a graded series of acetone. Polyester resin has been shown to be most suited as it results in impregnated samples of high stability which allow the preparation of accurate polished blocks or thin sections after cutting, grinding, and polishing. The polished surfaces are observed by epifluorescence microscopy or confocal laser scanning microscopy (CLSM). In order to separate specific signals related to the fluorophores bound to the probes and background fluorescence derived from soil compounds, special double filter excitation has shown to be useful [2].

To get a more detailed idea of the physico-chemical influences on the living conditions in soil microbial habitats, resin impregnated blocks have been utilized for other microscopic analyses resulting in a correlative approach of microanalysis (Figure 1). The complexity of the physical arrangement of pores in the undisturbed soil matrix can be analyzed after resin impregnation by either image analysis of soil thin sections or sophisticate d microfocus X-ray tomography [3, 4]. Both ways are subject to digital image analysis allowing for the characterization of different pore sizes and connectivity. Soils of different physical stages such as varying soil moisture contents or bulk densities have been analyzed this way with regard to the estimation of habitable pore space in the respective soils. Relevant information on the three-dimensional distribution and population density of soil microbes has been generated in combination with the spatial analysis of individual microbial cells in situ.

Resin impregnated soil samples have been further used for the analysis of elemental distribution in the undisturbed soil matrix which can be done by SEM-EDS on polished surfaces or soil thin sections. Using elemental mapping this spatial data can be correlated with the information generated by fluorescence microscopy or micro-CT. For the combination of the three dimensional CT data accurate alignment of spatial information is required which has been shown by Hapca et al. [5]. 
Paddy soils which are used for the cultivation of wetland rice show clear physical dynamics due to the typical procedure of management including puddling, irrigation, and drainage and are therefore analyzed by the correlative approach of microanalysis. Effects of these management factors on microbial dynamics were studied on the microscale throughout an entire growing season of wetland rice. Relevant groups of microorganisms being involved in the formation of greenhouse gases were analyzed in terms of abundance and activity as well as their population densities referring to the varying space in microbial habitats. The results showed a dramatic influence of the soil texture during the period of soil drainage on the population density of soil microorganisms causing stress and a shift within the population. In addition, areas close to the rice roots were found to be influenced by iron oxidation as a result of the aerenchymal function of the rice plant. This effect could clearly be shown by SEM-EDS mapping and was analyzed related to the concentration of iron formation with distance to the root channel.

The preparation of high quality polished blocks or thin sections by resin impregnation enables a detailed analysis of the spatial information on the level of microbial habitats in soil. In addition these resin impregnated soils could be analy zed with other techniques as well such as NanoSIMS or Gold-FISH $[6,7]$. Especially these two methods could allow for the microanalysis of microbial habitats on a $n$ ultrastructural level which would consequently address the interactions of single microbial cells with their microenvironment.

\section{References}

[1] T Eickhorst and R Tippkötter, Soil Biology \& Biochemistry 40 (2008), p. 1284-1293.

[2] T Eickhorst and R Tippkötter, Soil Biology \& Biochemistry 40 (2008), p. 1883-1891.

[3] T Eickhorst and R Tippkötter, Soil \& Tillage Research 102 (2009), p. 168-178.

[4] R Tippkötter et al., Soil \& Tillage Research 105 (2009), p. 12-20.

[5] S Hapca et al., Geoderma 164 (2011), p. 146-154.

[6] K Heister et al., Journal of Soils and Sediments 12 (2012), p. 35-47.

[7] H. Schmidt et al., Systematic and Applied Microbiology 35 (2012), p. 518-525.

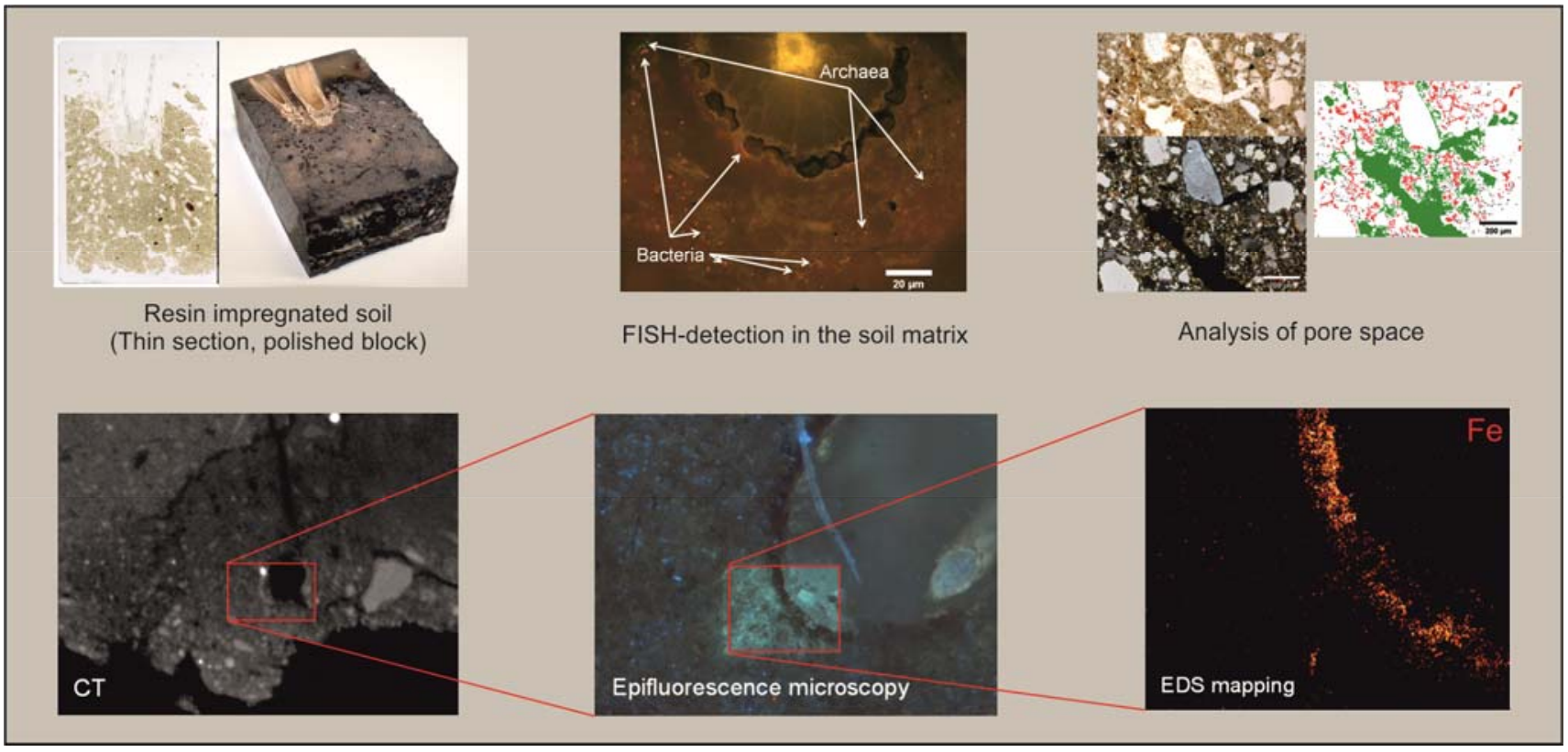

Figure 1. Correlative microanalyses on resin impregnated soil samples. 